\title{
ANALISIS USAHA PENANGKARAN BENIH PADI BERSERTIFIKAT KELOMPOK TANI HARAPAN JAYA DESA TEGAL REJO BELITANG OKU TIMUR
}

\author{
Munsiarum \\ Sekolah Tinggi Ilmu Pertanian Belitang \\ Jln.Kampus Pertanian No.3 Belitang Kab.OKU Timur Prov.Sumatera Selatan \\ e-mail: Munsiarumatmo77@gmail.com
}

\begin{abstract}
Abstrak
The purpose of this study was to calculate the amount of income and financial feasibility of the Harapan Jaya Farmer Group's Certified Rice Seed Breeding Business, Tegal Rejo Belitang Village, OKU Timur. The research was conducted in Tegal Rejo Village, Belitang District, East OKU Regency. The location selection was carried out purposively, namely in the village of Tegal Rejo and was carried out in March 2019. This research was conducted using a survey method. Sampling was carried out by using the census method for all populations, namely KT Harapan Jaya, which operates a certified rice seed breeding business in Tegal Rejo Village. The results showed that the total production cost incurred by certified rice seed producers in Tegal Rejo Village was IDR 652,183,535, business revenues amounted to IDR 714,308,000 so that the income received was IDR 62,124,465. The certified rice seed breeding business in Tegal Rejo Village is financially feasible to be developed, this can be seen from the calculation of the NPV value of the business of IDR 32,618,185, the IRR value is $76.93 \%$ and the Net B / C value is 1,68 .
\end{abstract}

Key Word : Business analysis, Rice Seed Breeding Business

\section{PENDAHULUAN}

Untuk menjamin ketahanan pangan yang masih dititikberatkan pada sasaran utama swasembada beras, maka pemerintah telah melakukan berbagai upaya, seperti intensifikasi, ekstensifikasi, dan diversifikasi. Program tersebut mampu mengubah Indonesia dari negara pengimpor beras terbesar menjadi berswasembada beras tersebut pada tahun 1984. Amat disayangkan prestasi tersebut berorientasi pada peningkatan produktivitas, belum pada peningkatan pendapatan petani (Anonim, 2002).

Benih merupakan suatu simbul dari suatu pemulaan yang merupakan inti dari kehidupan di dalam sebagai penyumbang kehidupan. Benih adalah biji tanaman yang digunakan untuk tujuan pertanaman. Benih memegang peranan penting dalam menentukan produksi yang akan diperoleh dalam berusahatani, didalamnya terkandung sifat-sifat yang akan tercermin dalam pertumbuhan dan produksi. Untuk menghasilkan benih unggul perlu penanganan benih yang baik. Sifat unggul pada benih dapat dipertahankan kemurniannya, benih dengan penanganan yang baik disebut benih unggul bermutu (Sutopo, 1988).

Benih merupakan salah satu komponen utama yang berperan penting dalam peningkatan kuantitas dan kualitas produksi padi, karenanya penggunaan benih varietas unggul yang bermutu (berlabel) sangat dianjurkan. Hal ini terkait dengan sifat-sifat yang dimiliki oleh varietas unggul, antara lain: berdaya hasil tinggi, tahan terhadap hama penyakit, dan rasa nasi enak (pulen). Benih sumber yang akan digunakan untuk pertanaman produksi benih harus satu kelas lebih tinggi dari kelas benih yang akan dipoduksi (Susilawati, 2010).

Dalam rangka peningkatan produksi pertanian melalui usaha pembinaan benih, Pemerintah Republik Indonesia No. 27 Tahun 1971 menetapkan di bentuknya Badan Benih Nasional (Sutopo, 1988 ). Untuk menunjang peningkatan produksi padi perlu adanya perbaikan varietas, teknik budidaya dan pengadaan benih yang baik dan bermutu. Dari tahun ke tahun usaha pertanaman padi terus ditingkatkan, baik tanaman padi lokal maupun tanaman padi unggul. Pemenuhan keperluan akan pangan tersebut diupayakan dengan jalan menambah produksi padi. Hal ini dilaksanakan salah satunya dengan cara intensifikasi dengan menerapkan penggunaan benih padi bermutu untuk mencapai produksi yang tinggi (Supangkat, 2003).

Seiring berjalannya waktu, perkembangan teknologi perbenihan telah mencapai kemajuan yang sangat pesat. Benih tidak lagi diperlakukan secara tradisional, namun telah berkembang menjadi industri yang dapat memberikan keuntungan dan lapangan pekerjaan yang cukup besar. Kesadaran akan pentingnya penggunaan benih yang bermutu (berlabel), mendorong tumbuh berkembangnya usaha perbenihan baik yang berskala besar maupun kecil. Di Indonesia, perkembangan usaha perbenihan meningkat cukup pesat dimana pemerintah membentuk usaha perbenihan seperti PT. Pertani, PT. Sang Hyang Sri dan lainnya sebagai langkah dalam usaha memenuhi akan kebutuhan benih yang bermutu. Pada akhirnya masyarakat pertanian pun ikut terlibat dalam usaha pengembangan benih bermutu dimana mereka menjadi petani penangkar benih yang bisa bermitra dengan perusahaan besar atau secara swadaya mengelola usaha perbenihannya (Hadi, 2009).

Penangkaran benih padi di Sumatera Selatan dilaksanakan pada setiap kabupaten oleh petani/penangkar atau produsen benih dalam bentuk perorangan atau badan hukum dan instansi pemerintah. Untuk menjamin kemurnian mutu yang diproduksi perlu dilakukan sertifikasi. Sertifikasi benih adalah proses pembuatan benih bermutu dan bersertifikat, mulai dari permohonan sampai pemasangan label. Tujuan sertifikasi benih adalah menjamin mutu fisiologis, fisik dan genetik serta menyediakan benih bermutu secara berkesinambungan yang diawasi oleh Balai Pengawasan dan Sertifikasi Benih Tanaman Pangan dan Hortikultura Propinsi Sumatera Selatan (Dinas Pertanian Tanaman Pangan Propinsi Sumatera Selatan, 2009).

Kabupaten OKU Timur sebagai lumbung padi di Sumatera Selatan memiliki potensi sumberdaya alam terutama lahan pertanian yang sangat besar. Kabupaten OKU Timur membutuhkan sarana produksi berupa 
benih padi unggul bersertifikat dalam jumlah yang cukup besar pula agar produksi pertanianya dapat maksimal. Pada era otonomi daerah saat ini, program pengembangan perbenihan lebih difokuskan di sentrasentra produksi yang ada di kabupaten. Oleh sebab itu maka perlu ditumbuhkan produsen-produsen benih disetiap wilayah kabupaten, sehingga diharapkan kebutuhan benih bermutu akan dapat terpenuhi. Permintaan kebutuhan benih bersertifikat di Kabupaten OKU Timur dari tahun ke tahun semakain meningkat, petani yang biasanya hanya menggunakan benih yang diproduksi dari hasil pertanaman sebelumnya kini mulai beralih menggunakan benih bersertifikat (berlabel). Petani merasakan bahwa padi yang dihasilkan benih bersertifikat lebih tinggi bila dibandingkan dengan benih tidak bersertifikat.

Desa Tegal Rejo merupakan salah satu desa yang berada di Kecamatan Belitang. Desa ini memiliki potensi cukup baik dalam bidang pertanian. Lahan pertanian yang mendukung untuk berusahatani padi dan masyarakatnya yang memiliki kesadaran yang cukup tinggi untuk menggunakan benih berlabel. Dalam rangka memenuhi keperluan akan benih padi unggul bermutu Dinas Pertanian Tanaman Pangan Kabupaten OKU Timur membina kelompok petani penangkaran padi yang tergabung dalam Kelompok Tani Harapan Jaya.

Kelompok Tani Harapan Jaya di Desa Tegal Rejo Kecamatan Belitang bertujuan untuk menyediakan benih berserifikat untuk penangkaran petani anggotanya, melakukan pembinaan dan pengawasan dalam proses sertifikasi dan kemudian membeli dan menampung gabah yang dihasilkan oleh petani penangkar untuk dilakukan pengolahan (processing) benih serta memasarkan benih tersebut. KT Harapan Jaya bertugas menyediakan benih unggul bagi petani di wilayah Kabupaten OKU Timur khususnya di wilayah Kecamatan Belitang dan sekitarnya. Dari tahun ke tahun usaha penangkaran benih yang dilakukan KT Harapan Jaya semakin meningkat dan semakin luas pemasarannya. Hal ini dapat diketahui dengan semakin luas areal penangkarannya dan semakin tinggi benih bersertifikat yang dihasilkannya. Dengan dasar inilah maka penulis merasa tertarik untuk melaksanakan penelitian dengan judul "Analisa Usaha Penangkaran Benih Padi Berserifikat KT. Harapan Jaya Desa Tegal Rejo Kecamatan Belitang Kabupaten OKU Timur".

\section{Rumusan Masalah}

Berdasarkan latar belakang di atas, maka rumusan masalah yang akan diambil dalam penelitian ini adalah :

1. Berapa besar biaya, penerimaan dan pendapatan yang diperoleh produsen benih padi bersertifikat KT. Harapan Jaya Desa Tegal Rejo Belitang OKU Timur?

2. Bagaimana kelayakan usaha produsen benih padi bersertifikat KT. Harapan Jaya Desa Tegal Rejo Belitang OKU Timur?

\section{METODE PENELITIAN}

\section{Tempat dan Waktu}

Penelitian ini telah dilaksanakan di Desa Tegal Rejo Kecamatan Belitang Kabupaten OKU Timur. Pemilihan lokasi dilakukan secara sengaja (purposive) dengan pertimbangan bahwa di desa tersebut terdapat Kelompok Tani Harapan Jaya yang memproduksi benih padi bersertifikat yang secara swadana telah mampu dan berkembang dalam menghasilkan dan memasarkan benih bersertifikat. Penelitian telah dilaksanakan pada Bulan Maret 2019.

\section{Metode Penelitian dan Penarikan Contoh}

Metode penelitian yang digunakan dalam penelitian ini adalah metode survei yang bertujuan untuk mendapatkan gambaran yang ada di lapangan dengan benar. Menurut Nazir (2011), metode survei adalah penyelidikan yang dilakukan untuk memperoleh fakta-fakta dan gejala-gejala yang ada dan mencari keterangan secara faktual dari suatu kelompok atau suatu daerah tertentu. Metode ini digunakan untuk mengetahui berapa besar biaya penggunaan faktorfaktor produksi pada usaha penangkaran benih padi bersertifikat yang digunakan berdasarkan data yang didapatkan dari petani sampel (responden). Sedangkan metode penarikan contoh dengan menggunakan metode sensus terhadap satu populasi produsen benih padi bersertifikat di Desa Tegal Rejo yaitu Kelompok Tani Harapan Jaya.

\section{Metode Pengumpulan Data dan Pengolahan Data}

Data yang digunakan dalam penelitian ini adalah data primer dan data sekunder. Data primer diperoleh melalui wawancara langsung dengan pengurus KT Harapan Jaya sebagai produsen benih dan petani penangkar yang dipandu dengan kuesioner, sedangkan data sekunder diperoleh dari penelusuran karya-karya ilmiah yang terkait dengan penelitian dan data-data yang diperoleh dari profil desa dan media komunikasi internet.

\section{Metode Pengolahan dan Analisis Data}

Data yang diperoleh dari penelitian dikelompokkan dan kemudian diolah menggunakan teknik komputerisasi dengan bantuan software microsoft excel yang akan ditampilkan dalam bentuk tabulasi sehingga dapat dijelaskan secara deskriptif.

1. Utk menjawab tujuan penelitian no 1 yaitu untuk mengetahui besarnya biaya, penerimaan dan pendapatan yang diperoleh produsen benih padi bersertifikat KT. Harapan Jaya Desa Tegal Rejo Belitang OKU Timur dihitung dengan menggunakan rumus sebagai berikut :

a. Biaya produksi dengan rumus:

$$
\begin{array}{ll}
\mathrm{TC}=\mathrm{FC}+\mathrm{VC} \\
\text { Dimana : } & \\
\text { TC } & =\text { Total Cost } \\
\text { FC } \quad=\text { Fixed Cost } \\
\text { VC } \quad=\text { Variabel Cost } /
\end{array}
$$

b. Penerimaan, digunakan rumus :

$$
\begin{array}{ll}
\text { TR= Q x P } & \\
\text { Dimana : } & \\
\text { TR } & =\text { Total Revenues } \\
\text { Q } & =\text { Quantity } \\
\text { P } & =\text { Price/Harga Jual }
\end{array}
$$


c. Pendapatan, digunakan rumus :

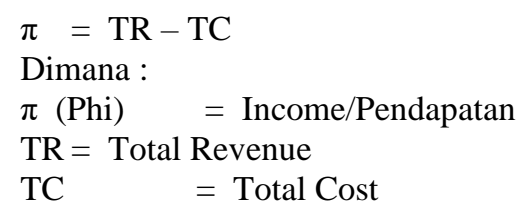

2. Untuk menjawab tujuan penelitian no 2 yaitu untuk menganalisa kelayakan usaha produsen benih padi bersertifikat KT. Harapan Jaya Desa Tegal Rejo Belitang OKU Timur.

d. $\mathrm{R} / \mathrm{C}$ rasio dihitung dengan menggunakan rumus .

$$
\begin{aligned}
& \mathrm{R} / \mathrm{C} \text { rasio }=\underline{\mathrm{TR}} \\
& \text { Dimana : } \mathrm{TC} \\
& \mathrm{R} / \mathrm{C}=\text { Return Cost Kasio } \\
& \mathrm{TR}=\text { Total Revenues } \\
& \mathrm{TC}=\text { Total Cost } \\
& \text { Dengan ketentuan : } \\
& \mathrm{R} / \mathrm{C} \text { Ratio }>1 \text { usahatani menguntungkan } \\
& \mathrm{R} / \mathrm{C} \text { Ratio }=1 \text { usahatani tidak untung dan tidak rugi } \\
& \text { (impas) } \\
& \mathrm{R} / \mathrm{C} \text { Ratio }<1 \text { usahatani rugi }
\end{aligned}
$$

e. Untuk menghitung NPV maka digunakan rumus :

$$
N P V=\sum \quad \frac{B t-C t}{(1+i)^{n}}-K o
$$

Dimana :

$\mathrm{NPV}=$ Net Present Value

Ko $=$ Kapital yang digunakan pada periode investasi.

$\mathrm{Bt}=$ Penerimaan pada tahun ke-t.

$\mathrm{Ct}=$ Pengeluaran discount faktor (bunga bank).

Dengan kriteria :

NPV > 0 maka usaha layak (feasible)

NPV $<0$ maka usaha tidak layak untuk

dilaksanakan

$\mathrm{NPV}=0$ maka usaha dalam keadaan impas

f. Untuk menghitung Internal Rate Ratio (IRR) maka digunakan rumus :

$$
I R R=i_{1}+\frac{N P V_{1}}{\left(N P V_{1-} N P V_{2}\right.} \times\left(i_{2}-i\right)
$$

Dimana :

$\mathrm{NPV}_{1}=\mathrm{NPV}$ pada tingkat discount rate tertinggi (positif)

$\mathrm{NPV}_{2}=\mathrm{NPV}$ pada tingkat discount rate terendah (negative).

$\mathrm{i}_{1} \quad=$ Discount rate tertinggi

$\mathrm{i}_{2}=$ Discount rate terendah

Dengan kriteria :

IRR > Cost of Capital maka usahatani layak (feasible).

IRR $<$ Cost of Capital maka usahatani tidak layak. g. Untuk menghitung nilai net $\mathrm{B} / \mathrm{C}$ ratio maka digunakan rumus :

$$
\text { Net } \mathrm{B} / \mathrm{C}=\frac{\sum \mathrm{NB}(+)}{\sum \mathrm{NB}\left(-_{-}\right)}
$$

Dimana :

$\Sigma \mathrm{NB}(+)=$ Net Benefit yang telah didiscount positif

$\Sigma$ NB (-) = Net Benefit yang telah didiscount negatif

Dengan kriteria :

Net $B / C>1$ usahatani layak

Net $B / C=1$ usahatani tidak untung dan tidak rugi (impas)

Net B/C $<1$ usahatani tidak layak

\section{HASIL DAN PEMBAHASAN}

\section{Pemasaran Benih Bersertifikat}

Secara garis besar terdapat 3 sistem pemasaran atau pola rantai pemasaran yang digunakan oleh Bapak Manik selaku produsen benih dalam memasaran produknya. Sistem atau pola pemasaran tersebut adalah

\section{Distribusi Langsung}

Sistem distribusi langsung yaitu Bapak Manik selaku produsen benih Ranum langsung menyalurkan atau memasarkan produknya langsung kepada petani di sekitar lingkungannya tanpa melalui perantara. Umumnya petani atau konsumen langsung mendatangi rumah Bapak Manik atau gudang tempat penyimpanan benih padi tersebut. Adapun harga yang ditawarkan yaitu $\mathrm{Rp} 55.000$ per kemasan $5 \mathrm{Kg}$.

\begin{tabular}{|l|l}
\hline Produsen & Konsumen \\
\hline
\end{tabular}

Gambar 1. Pola Pemasaran atau Distribusi Langsung (Pola 1).

\section{Distribusi Semi Langsung}

Sistem distribusi semi langsung yaitu Bapak Manik selaku produsen benih Ranum dalam memasarkan produknya kepada petani atau konsumen dengan melalui perantara pedagang eceran atau kioskios pertanian. Adapun harga yang ditawarkan kepada pedagang eceran atau kios-kios pertanian yaitu $\mathrm{Rp}$ 50.000 per kemasan $5 \mathrm{Kg}$. Umumnya pedagang eceran atau kios pertanian menjual kembali benih tersebut dengan harga antara Rp 55.000 s/d 65.000.

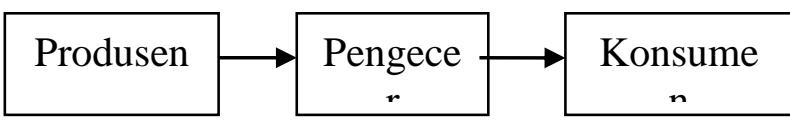

Gambar 2. Pola Pemasaran atau Distribusi Semi Langsung (Pola 2).

\section{Distribusi Tidak Langsung}

Sistem distribusi tidak langsung yaitu Bapak Manik selaku produsen benih padi Ranum menjual barangnya terlebih dahulu kepada agen atau pedagang besar kemudian agen atau pedagang besar tersebut menjual kepada pedagang eceran dan pedagang eceran menjual barang tersebut kepada konsumen. Adapun harga yang ditawarkan kepada agen atau pedagang 
besar yaitu Rp 45.000 per kemasan $5 \mathrm{Kg}$. Perbedaan harga antar saluran pemasaran bertujuan untuk menjaga kestabilan harga pasar.

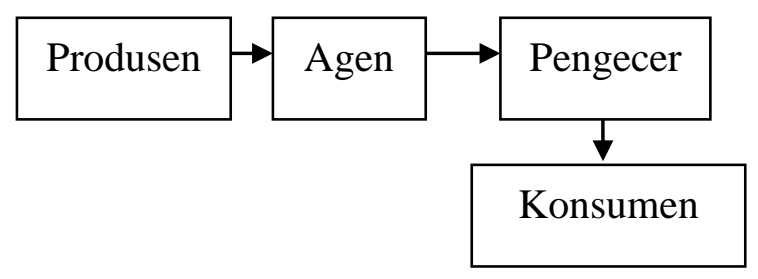

Gambar 3. Pola Pemasaran atau Distribusi Tidak Langsung (Pola 3).

Analisa Biaya Usaha Benih Padi Bersertifikat

\section{Biaya Tetap}

Dalam hasil penelitian yang dikelompokkan ke dalam biaya tetap (biaya investasi) di antaranya adalah biaya pembuatan gudang dan lantai jemur serta biaya pembelian peralatan. Analisa biaya dihitung selama 3 tahun usaha berjalan yaitu dimulai dari tahun 2013 sampai dengan awal tahun 2019. Dalam setiap tahunnya produsen benih KT. Harapan Jaya melakukan dua kali penanaman yauitu musim rendeng dan musim gadu sehingga terdapat dua kali proses produksi untuk menghasilkan benih padi bersertifikat.

Tabel 1. Biaya Tetap Usaha Penangkaran Benih Bersertifikat, 2019.

\begin{tabular}{|c|c|c|c|c|}
\hline \multirow{2}{*}{ No } & \multirow{2}{*}{ Biaya } & \multicolumn{3}{|c|}{ Tahun } \\
\hline & & 2013 & 2014 & 2015 \\
\hline \multirow[t]{19}{*}{ I. } & Biaya Investasi (Tetap) & & & \\
\hline & 1 Gudang & 70.000 .000 & - & \\
\hline & 2 Lantai Jemur & 30.000 .000 & - & \\
\hline & 3 Cleaner Seed & 9.000 .000 & - & \\
\hline & 4 Kipas Benih & 4.000 .000 & - & \\
\hline & 5 Moisture Tester & 2.500 .000 & - & \\
\hline & 6 Timbangan & 1.500 .000 & - & \\
\hline & 7 Sealer & 600.000 & - & 900.0 \\
\hline & 8 Mesin Jahit Karung & 800.000 & - & \\
\hline & 9 Terpal & 2.000 .000 & - & 1.500 .00 \\
\hline & 10 Sorok & 100.000 & 150.000 & 150.0 \\
\hline & 11 Sekop & 150.000 & - & 150.0 \\
\hline & 12 Ember & 70.000 & 70.000 & 70.0 \\
\hline & 13 Sapu & 75.000 & 75.000 & 75.0 \\
\hline & 14 Tenggok & 90.000 & 90.000 & 90.0 \\
\hline & 15 Lori & 500.000 & - & \\
\hline & 16 Dispenser & 150.000 & - & \\
\hline & 17 Pisau & 50.000 & 50.000 & 50.0 \\
\hline & Total Biaya Tetap & 121.585 .000 & 435.000 & 2.985 .0 \\
\hline
\end{tabular}

Berdasarkan hasil perhitungan pada Tabel 5 diketahui bahwa biaya tetap usaha penangkaran benih padi bersertifikat KT Harapan Jaya digunakan untuk investasi pembangunan gudang prosesing dan lantai jemur serta pembelian alat-alat untuk prosesing benih. Besarnya biaya tetap tahun 2013 adalah sebesar Rp 121.85.000, tahun 2014 sebesar Rp 435.000 dan tahun 2019 sebesar Rp 2.985.000 sehingga total biaya tetap usaha penangkaran benih padi bersertifikat KT. Harapan Jaya selama 3 tahun adalah sebesar Rp 125.005.000.

\section{Biaya Variabel}

Biaya variabel digunakan untuk operasional kegiatan usaha. Analisa biaya dihitung selama 3 tahun usaha berjalan yaitu dimulai dari tahun 2017 sampai dengan awal tahun 2019. Sedangkan untuk biaya variabel terdiri dari biaya pembelian GKP, biaya sarana produksi, biaya sertifikasi dan biaya tenaga kerja. Berikut komponen biaya variabel usaha penangkaran benih padi bersertifikat KT. Harapan Jaya :

Tabel 2. Biaya Variabel Usaha Penangkaran Benih Bersertifikat, 2019.

\begin{tabular}{lllll}
\hline & & \multicolumn{3}{c}{ Tahun } \\
\cline { 2 - 4 } No & Biaja & 2013 & 2014 & 2015 \\
\end{tabular}

\section{Biaja Operasional (Variabel)}

1 Pembelian GKP $\quad 110.350 .400 \quad 194.102 .200 \quad 124.196 .500 \quad 428.649 .100$

2 Karngo Besar $\quad 740.000 \quad 1.100 .000 \quad 400000 \quad 2280.000$

3 Karng Kecil $\quad 750,000 \quad 1,300.000 \quad 720.000 \quad 2.770 .000$

4 Plasilk Kemasan $\quad 6.840 .000 \quad 11.360 .000 \quad 6.4000 .000 \quad 24.476 .000$

5 TaliRafia $\quad 100.000 \quad 100.000 \quad 500000 \quad 250000$

6 Jarum $\quad 20.000 \quad 20.000 \quad 100000 \quad 500000$

7 Berang Karngy $\quad 50.000 \quad 50.000 \quad 250000 \quad 125.000$

8 Listitik $\quad 810.000 \quad 920.000 \quad 525.000 \quad 2.555000$

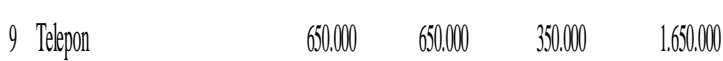

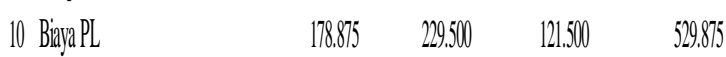

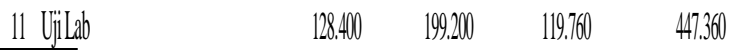

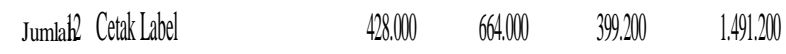

\begin{tabular}{|c|c|}
\hline 13 Solar & 550.000 \\
\hline
\end{tabular}

\begin{tabular}{|c|c|c|c|c|}
\hline 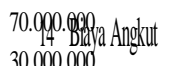 & 2.000 .000 & 2.750,000 & 150000 & 4.900 .000 \\
\hline 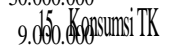 & 3.010 .000 & 5.45 .000 & 35000000 & 11.935 .000 \\
\hline 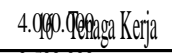 & 11.700 .000 & 19.500 .000 & 12370.000 & 43.300.000 \\
\hline $\begin{array}{l}2.500 .000 \\
1 \text { Trodaldiand Variabel }\end{array}$ & 138.305 .675 & $2389.955,900$ & 149.876.9000 & $527,178.535$ \\
\hline
\end{tabular}

Sumber ${ }_{800.000}$ : Olahan Data Primer, 2019. (Lampiran 6).

${ }^{3.500 .000}$ Berdasarkan hasil perhitungan pada Tabel 6 diketahui bahwa biaya variabel usaha penangkaran benih padi bersertifikat KT Harapan Jaya digunakan untuk $_{22.000}$ pembelian Gabah Kering Panen (GKP), pemhedian sarana produksi, biaya PL, uji laboratorium, cetak dabel dan biaya tenaga kerja dan biaya operasional lainfyb6at Besarnya biaya variabel tahun 2013 adalah sebes5.980 Rp 138.305.675, tahun 2014 sebesar Rp 238.995 .900 dan tahun 2019 sebesar Rp 149.876.960 sefing. 12.000 ga total biaya variabel usaha penangkaran benih padi bersertifikat KT. Harapan Jaya selama 3 tahun adalah sebesar Rp 527.178.535.

\section{Biaya Total Produksi}

Biaya total dalam usaha penangkaran benih padi bersertifikat KT. Harapan Jaya Desa Tegal Rejo terdiri dari biaya tetap ditambah dengan biaya variabel. Besarnya biaya total yang dikeluarkan oleh produsen benih padi bersertifikat dapat dilihat pada Tabel 7 sebagai berikut :

Tabel 7. Biaya Variabel Usaha Penangkaran Benih Bersertifikat, 2019.

\begin{tabular}{rrrrrr}
\hline \multirow{2}{*}{ No } & \multirow{2}{*}{ Uraian } & \multicolumn{3}{c}{ Tahun } & \multirow{2}{*}{ Jumlah } \\
\cline { 3 - 5 } & & \multicolumn{1}{c}{2013} & \multicolumn{1}{c}{2014} & \multicolumn{1}{c}{2015} & \\
\hline 1. & Biaya Tetap & 121.585 .000 & 435.000 & 2.985 .000 & 125.005 .000 \\
2. & Biaya Variabel & 138.305 .675 & 238.995 .900 & 149.876 .960 & 527.178 .535 \\
\hline & Jumlah & 259.890 .675 & 239.430 .900 & 152.861 .960 & 652.183 .535 \\
\hline
\end{tabular}

Sumber : Olahan Data Primer, 2019. (Lampiran 6). 
Berdasarkan hasil perhitungan pada Tabel 7 diketahui bahwa biaya total usaha penangkaran benih padi bersertifikat KT Harapan Jaya yang terdiri dari biaya tetap dan biaya variabel pada tahun 2013 adalah sebesar Rp 259.890.675, tahun 2014 adalah sebesar Rp 239.430.900 dan pada tahun 2019 adalah sebesar Rp 152.861 .960 sehingga total biaya produksi usaha penangkaran benih padi bersertifikat KT. Harapan Jaya selama 3 tahun adalah sebesar Rp 652.183.535.

\section{Produksi, Harga Jual, Penerimaan dan Pendapatan}

Adapun produksi, harga jual, biaya produksi, penerimaan, dan pendapatan usaha penangkaran benih padi bersertifikat KT. Harapan Jaya dapat dilihat pada Tabel 8.

Tabel 8. Produksi, Harga Jual, Penerimaan dan

\begin{tabular}{|c|c|c|c|c|c|}
\hline \multirow{3}{*}{$\mathrm{N}_{0}$} & Pen & & & & \multirow{3}{*}{ Jumlah } \\
\hline & \multirow{2}{*}{ Uraian } & \multicolumn{3}{|c|}{ Tahun } & \\
\hline & & 2013 & 2014 & 2015 & \\
\hline 1. & Produksi Benih $(\mathrm{Kg})$ & 21.400 & 33.200 & 19.960 & 74.560 \\
\hline 2. & Harga (Rp/Kg) & 9.500 & 9.500 & 9.800 & 9.580 \\
\hline 3. & Penerimaan (Rp) & 203.300 .000 & 315.400 .000 & 195.608.000 & 714.308 .000 \\
\hline 4. & Biaya Produksi (Rp) & 259.890 .675 & 239.430 .900 & 152.861 .960 & 652.183 .535 \\
\hline 5. & Pendapatan (Rp) & $(56.590 .675)$ & 75.969 .100 & 42.746 .040 & 62.124 .465 \\
\hline
\end{tabular}

Sumber : Olahan Data Primer, 2019. (Lampiran 6).

Berdasarkan hasil perhitungan pada Tabel 8 diketahui bahwa produksi benih pada tahun 2013 adalah sebesar $21.400 \mathrm{Kg}$ dan harga jual rata-rata benih adalah Rp 9.500/Kg sehingga diperoleh penerimaan sebesar Rp 203.300.000. Produksi benih tahun 2014 adalah sebesar $33.200 \mathrm{Kg}$ dan harga jual benih rata-rata adalah $\mathrm{Rp}$ 9.500/Kg sehingga diperoleh penerimaan sebesar $\mathrm{Rp}$ 203.300.000. Adapun produksi benih pada tahun 2019 adalah sebesar $19.960 \mathrm{Kg}$ dan harga jual benih rata-rata adalah sebesar $\mathrm{Rp}$ 9.800/Kg sehingga diperoleh penerimaan sebesar $\mathrm{Rp}$ 195.608.00. Total produksi benih selama 3 tahun adalah sebesar $74.560 \mathrm{Kg}$ dan harga jual rata-rata benih adalah $\mathrm{Rp} 9.580 / \mathrm{Kg}$ sehingga diperoleh total penerimaan selama 3 tahun adalah sebesar Rp 714.308.000.

Biaya total produksi usaha penangkaran benih padi bersertifikat KT Harapan Jaya pada tahun 2013 adalah sebesar $\mathrm{Rp} 259.890 .675$ dan penerimaan sebesar Rp 203.300.000 sehingga pada tahun 2013 mengalami kerugian sebesar Rp 56.950.675. Biaya total produksi tahun 2014 adalah sebesar Rp 239.430.900 dan penerimaan sebesar Rp 203.300.000 sehingga diperoleh pendapatan sebesar Rp 75.969.100. Adapun biaya total produksi pada tahun 2019 adalah sebesar Rp 152.861.960 dan penerimaan sebesar Rp 195.608.00 sehingga diperoleh pendapatan sebesar $\mathrm{Rp}$ 42.746.040. Adapun total pendapatan usaha penangkaran benih padi bersertifikat selama 3 tahun adalah sebesar $\mathrm{Rp}$ 62.124 .465

\section{G. Analisis Kelayakan Usaha Penangkaran Benih Padi Bersertifikat}

\section{Analisa NPV}

Net Present Value (NPV) atau nilai sekarang bersih adalah analisis manfaat finansial yang digunakan untuk mengukur layak tidaknya suatu usaha dilaksanakan dilihat dari nilai sekarang (present value). Kriteria kelayakan dari usaha ini adalah: proyek layak jika NPV lebih besar dari nol (positif) dan sebaliknya proyek tidak layak jika NPV nilainya lebih kecil dari nol (negatif).

Tabel 9. Analisa Kelayakan

\begin{tabular}{|c|c|c|c|c|c|}
\hline \multirow{2}{*}{ No } & \multirow{2}{*}{ Biaya dan Manfaat } & \multicolumn{3}{|c|}{ Tahun } & \multirow[b]{2}{*}{ Jumlah } \\
\hline & & 2017 & 2018 & 2019 & \\
\hline 1 & Biaya Investasi & $121,585,000$ & 435,000 & $2,985,000$ & $125,005,000$ \\
\hline 2 & Biaya 0perasional & $138,305,675$ & $238,995,900$ & $149,876,960$ & $527,178,535$ \\
\hline 3 & Total Biaya & $259,890,675$ & $239,430,900$ & $152,861,960$ & $652,183,535$ \\
\hline 4 & Penerimaan & $203,300,000$ & $315,400,000$ & $195,608,000$ & $714,308,000$ \\
\hline 5 & Pendapatan & $(56,590,675)$ & $75,969,100$ & $42,746,040$ & $62,124,465$ \\
\hline \multirow[t]{9}{*}{6} & Kelayakan & & & & \\
\hline & NPV df $18 \%$ & & & & 32618185.24 \\
\hline & NPV (-) $77 \%$ & & & & -14711.5022 \\
\hline & Compounding Faktor $18 \%$ & 1.3924 & 1.18 & 1 & 0 \\
\hline & PVR & 283074920 & 372172000 & 195608000 & 850854920 \\
\hline & PVC & 361871775.9 & 282528462 & 152861960 & 797262197.9 \\
\hline & PVB & -78796855.87 & 89643538 & 42746040 & 53592722.13 \\
\hline & Net $B / C$ & 0 & 0 & 0 & 1.680137825 \\
\hline & IRR & 0 & 0 & 0 & 0.769734017 \\
\hline
\end{tabular}

Sumber : Olahan Data Primer, 2019. (Lampiran 6).

Hasil analisis pada Tabel 9 diperoleh nilai investasi usaha penangkaran benih padi bersertifikat selama 3 tahun adalah sebesar Rp 125.005.000. Biaya operasional selam 3 tahun adalah sebesar $\mathrm{Rp}$ 527.178.535 sehingga diperoleh biaya total sebesar Rp 652.183.535 Total penerimaan usaha usaha penangkaran benih padi bersertifikat selama 3 tahun adalah sebesar Rp 714.308.000 sehingga diperoleh total pendapatan usaha selama 3 tahun adalah sebesar Rp 62.124 .465

Dari perhitungan NPV selama tiga tahun usaha yaitu tahun 2013, tahun 2014 dan sampai bulan April 2019 dengan tingkat bunga $18 \%$ (NPV df 18\%) maka diperoleh nilai NPV adalah sebesar Rp 32.618.185. Berdasarkan analisis diperoleh nilai NPV $>0$, Hal ini menunjukan bahwa usaha penangkaran benih padi bersertifikat ini menguntungkan dan layak secara financial untuk diteruskan.

\section{Analisa IRR (Internal Rate of Return)}

Kriteria yang dipakai untuk menunjukkan bahwa suatu usaha layak dijalankan adalah jika nilai IRR lebih besar dari tingkat suku bunga yang berlaku pada saat usaha tersebut diusahakan (Gittinger, 1993). Jadi, jika IRR lebih tinggi dari tingkat bunga bank, maka usaha yang direncanakan atau yang diusulkan layak secara finansial untuk dilaksanakan.

Berdasarkan perhitungan pada Tabel 9 diperoleh nilai NPV positif (+) adalah sebesar Rp 32.618.185 dan nilai NPV negatif (-) terkecil dengan nilai interest $77 \%$ adalah sebesar $\mathrm{Rp}$ (14.712,). Berdasarkan hasil perhitungan dengan menggunakan Compounding Faktor 18\%, maka diperoleh nilai IRR usaha penangkaran benih padi bersertifikat adalah sebesar 76,93\% yang berarti nilai IRR lebih besar daripada nilai SOCC (Social Opportunity Cost of Capital) sebesar $18 \%$. Hal ini menunjukan bahwa usaha penangkaran benih padi bersertifikat KT. Harapan Jaya di Desa Tegal Rejo Kecamatan Belitang menguntungkan dan layak (feasible) secara finansial untuk dikembangkan.

\section{Analisa Net $B / C$}

Net Benefit Cost Ratio adalah penilaian yang dilakukan untuk melihat tingkat efisiensi penggunaan biaya berupa perbandingan jumlah nilai bersih sekarang yang positif dengan jumlah nilai bersih sekarang yang negatif, atau dengan kata lain Net $B / C$ adalah perbandingan antara jumlah NPV positif dangan jumlah NPV negatif dan ini menunjukkan gambaran berapa 
kali lipat benefit akan kita peroleh dari cost yang kita keluarkan. Kriteria ini memberikan pedoman bahwa suatu proyek akan dipilih apabila nilai $(\mathrm{Net} B / \mathrm{C}>0)$, sebaliknya bila suatu proyek memberikan nilai (Net $B / C<0)$, maka proyek tidak akan diterima (diteruskan). Tabel 10. Analisa Net B/C

\begin{tabular}{ccc}
\hline No & Tahun & $\begin{array}{c}\text { Nilai Present Value } \\
\text { Benefit (PVB) }\end{array}$ \\
\hline 1. & 2017 & $-78.796 .855,87$ \\
2. & 2018 & $89.643 .538,00$ \\
3. & 2019 & $42.746 .040,00$ \\
\hline
\end{tabular}

Nilai Net B/C $\quad 1,68$

Sumber : Olahan Data Primer, 2019. (Lampiran 6).

Nilai net B/C diperoleh dengan menjumlahkan nilai PVB positif $(+)$ kemudian hasilnya dibagi dengan nilai PVB negatif (-). Berdasarkan hasil perhitungan, diperoleh nilai Net B/C adalah sebesar 1,68. Nilai Net $\mathrm{B} / \mathrm{C}>0$ berarti usaha penangkaran benih padi bersertifikat KT. Harapan Jaya di Desa Tegal Rejo menguntungkan dan layak dikembangkan. Berdasarkan perhitungan analisa NPV, IRR dan Net B/C menunjukan bahwa usaha penangkaran benih padi bersertifikat KT. Harapan Jaya di Desa Tegal Rejo Kecamatan Belitang Kabupaten OKU Timur menguntungkan dan layak secara finansial.

\section{KESIMPULAN DAN SARAN}

\section{A. Kesimpulan}

Berdasarkan hasil penelitian dan analisis yang telah dilakukan, maka dapat ditarik kesimpulan sebagai berikut ;

1. Biaya total produksi yang dikeluarkan oleh produsen benih padi bersertifikat di Desa Tegal Rejo adalah sebesar Rp 652.183.535, penerimaan usaha adalah sebesar Rp 714.308.000 sehingga pendapatan yang diterima adalah sebesar $\mathrm{Rp}$ 62.124.465.

2. Usaha penangkaran benih padi bersertifikat di Desa Tegal Rejo layak (feasible) secara finansial untuk dikembangkan, hal ini diketahui dari nilai NPV usaha sebesar Rp 32.618.185, nilai IRR sebesar 76,93\% dan nilai Net B/C sebesar 1,68.

\section{B. Saran}

Adapun saran yang dapat disampaikan oleh penulis adalah :

1. Produsen benih padi bersertifikat diusahakan untuk meningkatkan jumlah produksi benih padi yang dihasilkan yaitu dengan memperluas areal penangkarannya.

2. Produsen benih padi bersertifikat harus terus menjaga dan meningkatkan kualitas produksi benih padi yang dihasilkan.

\section{DAFTAR PUSTAKA}

Anonim. 2002. Pusat Standarisasi dan Akreditasi Sistem Pangan Organik. www.deptan.go.id.Pusat Standarisasi dan Akreditasi Sistem Pangan Organik. Diakses 17 April 2019.
2009. Laporan Tahunan. Dinas Pertanian Tanaman Pangan Provinsi Sumatera Selatan.

Gittinger, J. P. 1986. Analisis Ekonomi Proyek-proyek Pertanian. UI Press. Jakarta.

Hadi, M. 2009. Kajian Ekonomi Usaha Penangkaran Benih Padi Unggul di Kabupaten Banjar. Thesis. Universitas Lambung Mangkurat. Banjarbaru.

Ibrahim, Y. 1998. Studi Kelayakan Bisnis. Rineka Cipta. Jakarta.

Nazir, M. 2011. Metode Penelitian. Ghalia Indonesia. Bogor.

Soekartawi. 2002. Analisis Usahatani. UI-Press. Jakarta.

Supangkat. 2003. Sumber Daya Manusia. Penebar Swadaya. Jakarta.

Susilawati, N. 2010. Produksi Benih Padi. Balai Pengkajian Tehnologi Pertanian Banten. http://banten.litbang.deptan.go.id. Diakses pada 15 April 2019

Sutopo, L. 1988. Teknologi Benih. Rajawali Pers. Jakarta. 